\title{
Article \\ Depth-Sensing Hardness Measurements to Probe Hardening Behaviour and Dynamic Strain Ageing Effects of Iron during Tensile Pre-Deformation
}

\author{
Lyubomira Veleva ${ }^{1}$, Peter Hähner ${ }^{1, * \mathbb{D}}$, Andrii Dubinko ${ }^{2}$, Tymofii Khvan ${ }^{2}$, Dmitry Terentyev ${ }^{2}$ and $^{2}$ \\ Ana Ruiz-Moreno ${ }^{1}$ (D)
}

check for updates

Citation: Veleva, L.; Hähner, P.; Dubinko, A.; Khvan, T.; Terentyev, D.; Ruiz-Moreno, A. Depth-Sensing Hardness Measurements to Probe Hardening Behaviour and Dynamic Strain Ageing Effects of Iron during Tensile Pre-Deformation. Nanomaterials 2021, 11, 71. https://doi.org/ 10.3390/nano11010071

Received: 16 November 2020 Accepted: 25 December 2020 Published: 30 December 2020

Publisher's Note: MDPI stays neutral with regard to jurisdictional clai$\mathrm{ms}$ in published maps and institutional affiliations.

Copyright: (C) 2020 by the authors. Licensee MDPI, Basel, Switzerland. This article is an open access article distributed under the terms and conditions of the Creative Commons Attribution (CC BY) license (https:// creativecommons.org/licenses/by/ $4.0 /)$.
1 European Commission, Joint Research Centre, Directorate G: Nuclear Safety and Security, Westerduinweg 3, 1755 LE Petten, The Netherlands; lyubomiraveleva@gmail.com (L.V.); ana.ruiz-moreno@ec.europa.eu (A.R.-M.)

2 SCK•CEN, Nuclear Materials Science Institute, Boeretang 200, 2400 Mol, Belgium; andrii.dubinko@sckcen.be (A.D.); tymofii.khvan@sckcen.be (T.K.); dmitry.terentyev@sckcen.be (D.T.)

* Correspondence: peter.haehner@ec.europa.eu; Tel.: +31-224-56-5217

\begin{abstract}
This work reports results from quasi-static nanoindentation measurements of iron, in the un-strained state and subjected to $15 \%$ tensile pre-straining at room temperature, $125^{\circ} \mathrm{C}$ and $300{ }^{\circ} \mathrm{C}$, in order to extract room temperature hardness and elastic modulus as a function of indentation depth. The material is found to exhibit increased disposition for pile-up formation due to the pre-straining, affecting the evaluation of the mechanical properties of the material. Nanoindentation data obtained with and without pre-straining are compared with bulk tensile properties derived from the tensile pre-straining tests at various temperatures. A significant mismatch between the hardness of the material and the tensile test results is observed and attributed to increased pile-up behaviour of the material after pre-straining, as evidenced by atomic force microscopy. The observations can be quantitatively reconciled by an elastic modulus correction applied to the nanoindentation data, and the remaining discrepancies explained by taking into account that strain hardening behaviour and nano-hardness results are closely affected by dynamic strain ageing caused by carbon interstitial impurities, which is clearly manifested at the intermediate temperature of $125^{\circ} \mathrm{C}$.
\end{abstract}

Keywords: nanoindentation; unalloyed iron; strain hardening; atomic force microscopy; pile-up; dynamic strain ageing

\section{Introduction}

Nanoindentation constitutes one of the micromechanical testing techniques used to study mechanical properties at small scales and/or of small specimens. At these scales, the understanding of the dislocation mechanisms acting during indentation and their interaction with the specimen's surface is key to comprehending the mechanical response of the material [1-3]. Continuous improvements in methodologies to record and analyse load-displacement curves are promoting nanoindentation to complement conventional mechanical testing in materials selection and design [4]. Furthermore, the technique allows probing of positions with varying properties, for instance, across the thickness of a larger component. While the measured indentation hardness depends on the material properties, like elastic modulus, yield stress and strain hardening behaviour, it is also affected by the indenter geometry and size.

The attractiveness of nanoindentation as a mechanical test technique relates to the convenience of providing large amount of data with a comparatively low amount of effort and time. On the downside, nanoindentation data are affected by the indentation size effect (ISE) [5-7], which has to be determined in order to compare with mechanical properties at a larger scale. Moreover, the formation of pile-ups of material around the indenter mark can take various degrees and largely affect the apparent hardness, thereby invalidating 
nanoindentation for quantitative mechanical property assessment, unless the technique is complemented by costly atomic force microscopy (AFM). It is important to note that nano-scale physical processes related to the dislocation motion, self-pinning and multiplication and their interactions with grain boundaries drive the formation of the pile-ups. The operation of these nano-scale mechanisms may lead to the accumulation of considerable and non-negligible plastic deformation depending on the initial microstructure (i.e., dislocations, point defects impurities, grain boundaries) and ability for plastic deformation (Peierls stress, crystallographic structure).

This work reports results from quasi-static nanoindentation measurements of unalloyed iron at room temperature, performed in order to extract hardness and elastic modulus as functions of indentation depth (size effect), as well as to assess the effect of pre-deformation. This assessment turns out to be complicated by the pile-up formation during nanoindentation, because an increased disposition for pile-up formation [8] of the iron following pre-straining is observed, which leads to significant increases of the apparent hardness and indentation modulus levels.

As the present investigation uses nanoindentation for mechanical property correlation, grain boundaries can be expected to affect load-displacement curves, indentation Young's moduli, von Mises stresses, and pile-up formation, see for instance the work of Liu et al. [9] where this was studied by crystal plasticity finite element simulation of bicrystal deformation during nanoindentation. Pile-up behaviour is also anisotropic due to the activation of different slip systems and, hence, pile-up patterns depend on the grain orientations as demonstrated through crystal plasticity modelling in ref. [10]. Under these circumstances, nanoindentation can either be complemented by grain orientation information from electron backscatter diffraction (EBSD) or like in the present work, by averaging over multiple grains with random orientations. To relate nanohardness data to tensile properties, constraint effects [11], ISE [12], and grain size effects [13] can be taken into account.

The effects of pile-up emergence on the mechanical properties of the material have therefore been investigated, in order to derive meaningful hardness results, which are adjusted for artefacts from the pile-up formation. Strain hardening behaviour and nanoindentation hardness results are interpreted in relation to dynamic strain ageing (DSA) behaviour of the material [14,15].

\section{Materials and Methods}

\subsection{Material}

The unalloyed Fe cast material used for this study was produced by OCAS NV in Belgium in an induction vacuum furnace and designated as G379. A piece from the produced material was introduced in a pre-heated furnace at $1200{ }^{\circ} \mathrm{C}$ for $1 \mathrm{~h}$ and hot rolled without interruption. The as-received sheet was subsequently air-cooled to room temperature. The final dimensions of the sheet were approx. $10 \mathrm{~mm}$ (height) $\times 250 \mathrm{~mm}$ (width) $\times 600 \mathrm{~mm}$ (length). The average grain size of the material was determined as 86 $\mu \mathrm{m}$ by linear intercept method applied to an EBSD map of the material.

The chemical composition in the middle of a slice cut from between the head and the body of the ingot was determined by OCAS NV by means of spark source optical emission spectroscopy (SS-OES) to quantify all elements except $\mathrm{Ni}$, Si and $\mathrm{Al}$, and by inductively coupled plasma optical emission spectroscopy (ICP-OES) giving access to Ni, Si and Al concentrations. The results are shown in Table 1; all other elements were below the SS-OES detection limits, except for the $S$ content, which was between 10 and 15 ppm for this cast. It is important to point out that a C impurity content of $0.0067 \mathrm{wt}$. \% would correspond to a concentration of $313 \mathrm{ppm}$, which is significant in inducing dynamic strain ageing [15]. 
Table 1. Chemical composition of Fe (G379) and detection limits of impurities using SS-OES and ICP-OES, in wt.\%.

\begin{tabular}{cccccccc}
\hline $\mathbf{C r}$ & $\mathbf{N i}$ & $\mathbf{P}$ & $\mathbf{A l}$ & $\mathbf{S i}$ & $\mathbf{V}$ & $\mathbf{W}$ & $\mathbf{C u}$ \\
\hline 0.002 & 0.007 & 0.003 & 0.023 & 0.001 & $<0.0109$ & $<0.0099$ & $<0.0091$ \\
\hline $\mathbf{M o}$ & $\mathbf{C o}$ & $\mathbf{C}$ & $\mathbf{N b}$ & $\mathbf{T i}$ & As & Sn & \\
\hline$<0.0082$ & $<0.0080$ & $<0.0067$ & $<0.0036$ & $<0.0020$ & $<0.0012$ & $<0.0010$ & \\
\hline
\end{tabular}

\subsection{Mechanical Deformation of Specimens}

G379 Fe specimens were pre-strained to $15 \%$ by applying uniaxial tensile deformation. The mechanical straining was performed on an Instron electro-mechanical universal test machine (Instron, Norwood, MA, USA) equipped with an environmental chamber and subject to regular qualification and calibration procedures according to Belgian accreditation rules (BELAC). Sample elongation was measured by the pull rod displacement. The force was measured by a load cell with a maximum capacity of $50 \mathrm{kN}$. Uniaxial tensile tests at a crosshead displacement rate of $0.2 \mathrm{~mm} / \mathrm{min}$ were performed on flat dog-bone shaped specimens featuring a gauge length of $60 \mathrm{~mm}$ and a cross-section of $1.1 \times 12 \mathrm{~mm}^{2}$. The overall length of the specimens was $120 \mathrm{~mm}$. The tests were carried out at room temperature, $125^{\circ} \mathrm{C}$ and $300^{\circ} \mathrm{C}$ in air up to $15 \%$ deformation. The plastic deformation was uniform across the whole gauge section as confirmed by the dimensional check after the test.

\subsection{Microstructural Characterization}

The microstructure of as-received and plastically deformed samples was studied by transmission electron microscopy (TEM) to provide information on the dislocation density and possible grain refinement caused by the plastic deformation. The pieces for TEM samples were mechanically polished from both sides using SiC paper with grit sizes of 220, 500, 1200 and 4000 to achieve 70-100 $\mu \mathrm{m}$ thickness and further cut with a wire cutter into pieces to fit 3 $\mathrm{mm}$ TEM grids. They were polished again from both sides with $4000 \mathrm{SiC}$ paper to remove the remnants of a glue, rinsed in acetone and ethanol and then glued on $3 \mathrm{~mm}$ copper grids with an aperture of $1 \mathrm{~mm}$. Finally, TEM specimens were polished electrochemically with a solution of 1.5 wt. $\% \mathrm{NaOH}$ in water with an applied voltage of $30 \mathrm{~V}$.

The specimens were investigated with a JEOL 3010 TEM (JEOL Ltd., Tokyo, Japan) operating at $300 \mathrm{kV}$. The average dislocation density was measured following the methodology used in [16-18]. Each calculation requires a TEM micrograph, the corresponding diffraction pattern and a convergent beam electron diffraction (CBED) pattern. Several calculations at different areas of the specimen were performed to get an average dislocation density. In the software DigitalMicrograph (Gatan Inc., Pleasanton, CA, USA), provided with the image sensor of a microscope, a circle is drawn randomly in an image and the number of intersections of it with dislocation lines is counted. The dislocation density is then calculated as $\rho=2 N / L t$, where $N$ is the number of intersections of the circle with dislocation lines, $L$ the perimeter of the circle, $t$ the local thickness of the specimen at the area of the image. The perimeter is automatically calculated by the software, while the local thickness of the specimen is determined from the CBED pattern and the diffraction pattern.

Patterns of the dislocation microstructure after the plastic deformation are provided in Figure 1. In the non-deformed samples, the dislocations are homogeneously distributed, and their density is about $10^{12} \mathrm{~m}^{-2}$. In the pre-deformed samples, the dislocations appear to be heterogeneously distributed for all deformation temperatures, i.e., some regions exhibit high density with dislocation pile-ups and tangles, whereas other regions contain rather low dislocation densities of about $10^{12} \mathrm{~m}^{-2}$, comparable to the density in the non-deformed material. Following the method described above, the mean density was determined to amount to $2 \times 10^{14} \mathrm{~m}^{-2}, 3.7 \times 10^{14} \mathrm{~m}^{-2}$ and $8 \times 10^{13} \mathrm{~m}^{-2}$, for samples deformed to $15 \%$ of strain at $\mathrm{RT}, 125^{\circ} \mathrm{C}$ and $300^{\circ} \mathrm{C}$, respectively. 

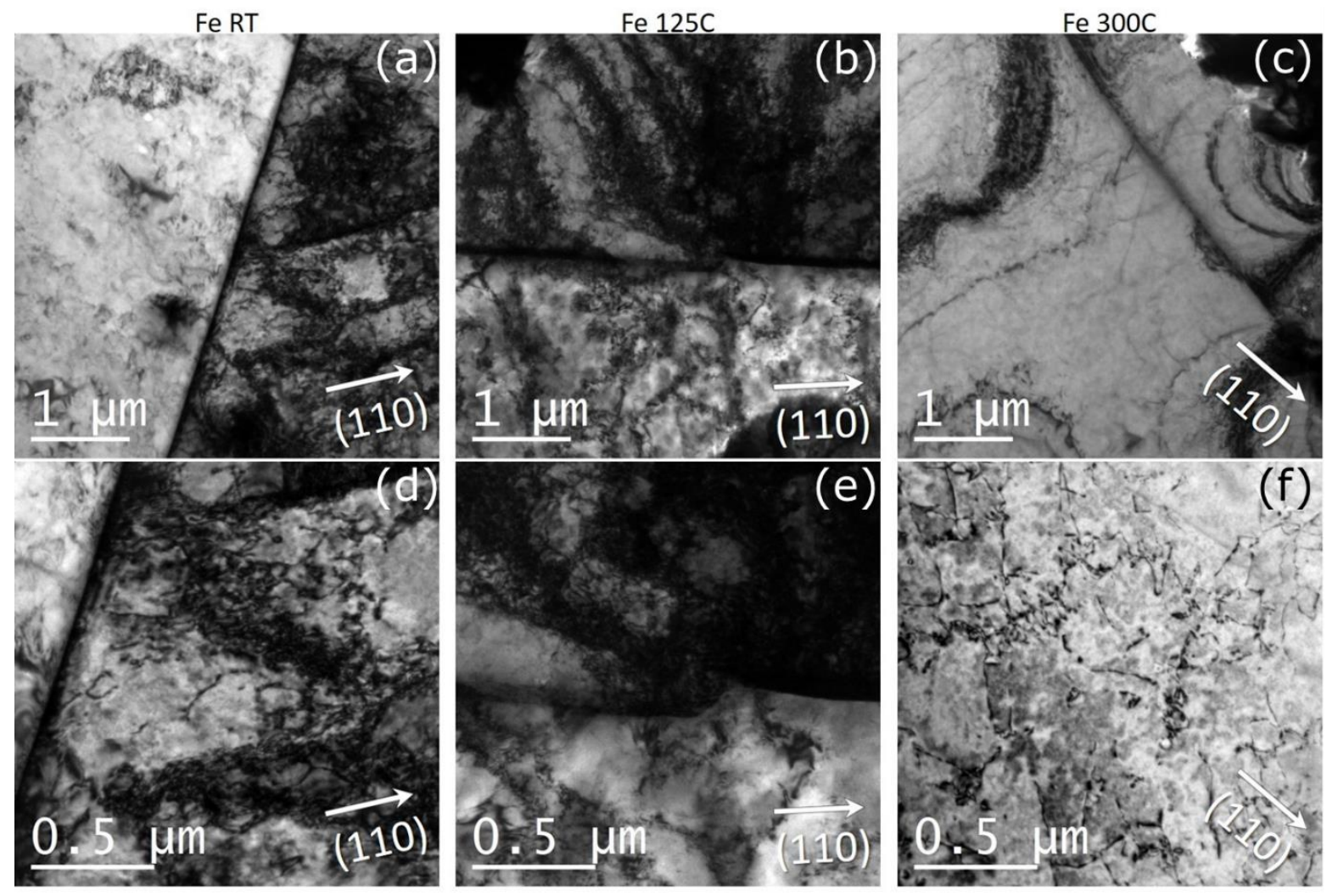

Figure 1. TEM micrographs showing typical dislocation patterns in plastically deformed Fe. (a,d)—deformed at room temperature, (b,e) deformed $125^{\circ} \mathrm{C},(\mathbf{c}, \mathbf{f})$ deformed at $300{ }^{\circ} \mathrm{C}$.

\subsection{Nanoindentation Testing}

For nanoindentation testing and AFM of the indents, three samples of $10 \times 10 \times 1 \mathrm{~mm}^{3}$ were cut from the gauge length (deformed part of the specimen) and three other samples were taken from the shoulder (not deformed) of the tensile specimens, as described in Table 2.

Table 2. Samples for nanoindentation and AFM from tensile specimens.

\begin{tabular}{cccc}
\hline $\begin{array}{c}\text { Specimen } \\
\text { Name }\end{array}$ & Tensile Specimen ID & Temperature & Pre-Deformation \\
\hline Fe-AR-RT & 1 & RT $\left(24^{\circ} \mathrm{C}\right)$ & Non-deformed \\
\hline Fe-15\%-RT & 2 & RT $\left(24^{\circ} \mathrm{C}\right)$ & $15 \%$ \\
\hline Fe-AR-125 & 3 & $125^{\circ} \mathrm{C}$ & Non-deformed \\
\hline Fe-15\%-125 & 4 & $125^{\circ} \mathrm{C}$ & $15 \%$ \\
\hline Fe-AR-300 & 5 & $300^{\circ} \mathrm{C}$ & Non-deformed \\
\hline Fe-15\%-300 & 6 & $300^{\circ} \mathrm{C}$ & $15 \%$ \\
\hline
\end{tabular}

The sample surface preparation sequence is summarized in Table 3. The surface was first ground with abrasive paper with grit 320 (SiC), followed by grinding with grit 800 , then mechanically polished with $6 \mu \mathrm{m}, 3 \mu \mathrm{m}$ and final polishing with $1 \mu \mathrm{m}$ diamond paste.

Indentation tests were performed using a high temperature Ultra nanoindentation test device UNHT HTV (Anton Paar GmbH, Graz, Austria) with dual indenters (indentation and active reference tip) that provides active surface referencing and thereby minimizes drift and frame compliance. A Berkovich diamond self-similar tip was used for the indentation tests. The tip area function and the frame compliance were calibrated according to ISO 14577-2 using a DataSure IIT kit of certified reference materials (tungsten and fused silica) from National Physical Laboratory in an iterative way [19]. 
Table 3. Surface preparation sequence of G379 for nanoindentation.

\begin{tabular}{ccccc}
\hline Cloth & Suspension & Force [N] & Rotation [rpm] & Time [min] \\
\hline Sic foil & Water & 80 & $\begin{array}{c}300 / 150 \\
\text { Co-rotation }\end{array}$ & 3 \\
\hline MD-Largo & DiaPro All & 120 & $\begin{array}{c}150 / 150 \\
\text { Co-rotation }\end{array}$ & 5 \\
\hline MD-Dac & DiaPro Dac 3 & 90 & $\begin{array}{l}150 / 150 \\
\text { Co-rotation }\end{array}$ & 5 \\
\hline MD-Nap & DiaPro Nap 1 & 60 & $\begin{array}{l}150 / 150 \\
\text { Counter- } \\
\text { rotation }\end{array}$ & 3 \\
\hline MD-Chem & OPS & 40 & $\begin{array}{l}150 / 150 \\
\text { Counter- } \\
\text { rotation }\end{array}$ & 2.5 \\
\hline
\end{tabular}

Force-controlled single cycle (FSC) measurements were carried out with linear loading up to various maximum forces $F_{\max }$ and concomitant contact depths $h_{\mathrm{c}}$ with a loading time of $30 \mathrm{~s}$, a dwell time of $10 \mathrm{~s}$, and subsequent unloading within $30 \mathrm{~s}$. Five maximum force levels of $1 \mathrm{mN}, 5 \mathrm{mN}, 10 \mathrm{mN}, 50 \mathrm{mN}$ and $100 \mathrm{mN}$ were applied. For each condition, ten repeat indents were randomly placed over the surface of the material and the results averaged. Random positioning of indents was achieved by spacing them equidistantly $50 \mu \mathrm{m}$ apart in a square lattice irrespective of the underlying polycrystalline grain structure. The lattice spacing was chosen with a view to the grain size and to avoid mutual interaction of even the largest indentations.

Figure 2 illustrates the indentation force vs. depth curves measured for two sets of repeated indentations to $100 \mathrm{mN}$ maximum force on the Fe-AR-125 and the Fe-15\%-125 specimen, respectively. One notes good repeatability as plastic anisotropy of the material is low, noting that the hardness spread increases significantly after pre-deformation. This effect is most pronounced for the intermediate temperature of $125^{\circ} \mathrm{C}$ illustrated here, $\mathrm{cf}$. Figure 3.

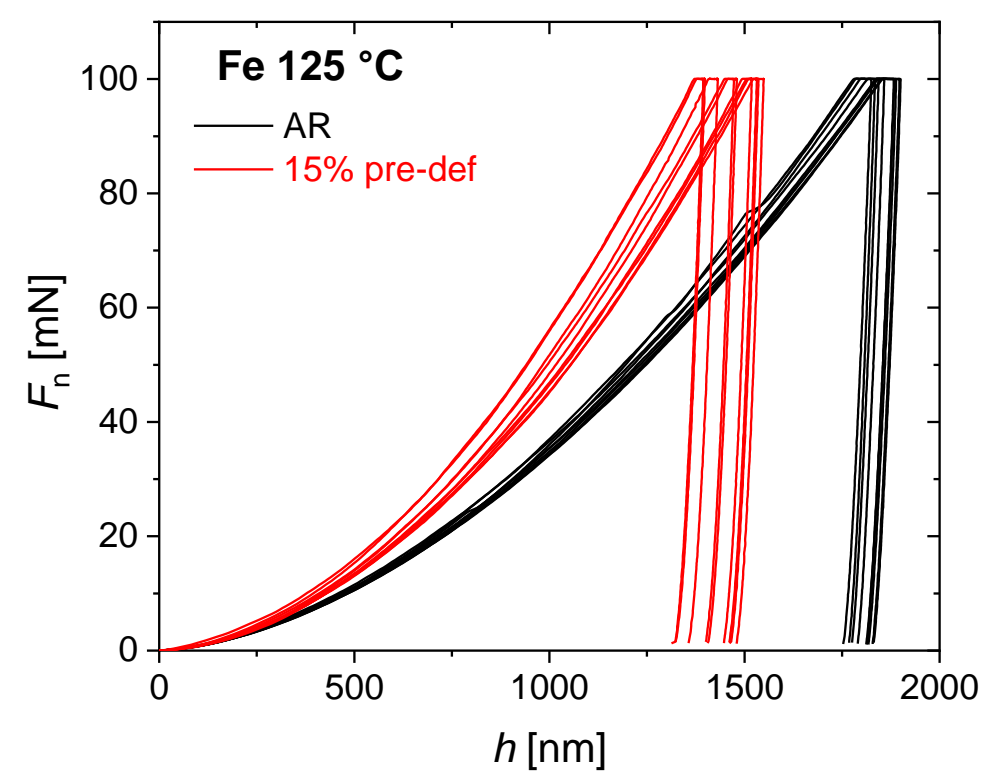

Figure 2. Indentation force $v$ s. depth curves for two sets of repeated indents to $100 \mathrm{mN}$ maximum force on the Fe-AR-125 and the Fe-15\%-125 specimen, respectively. 


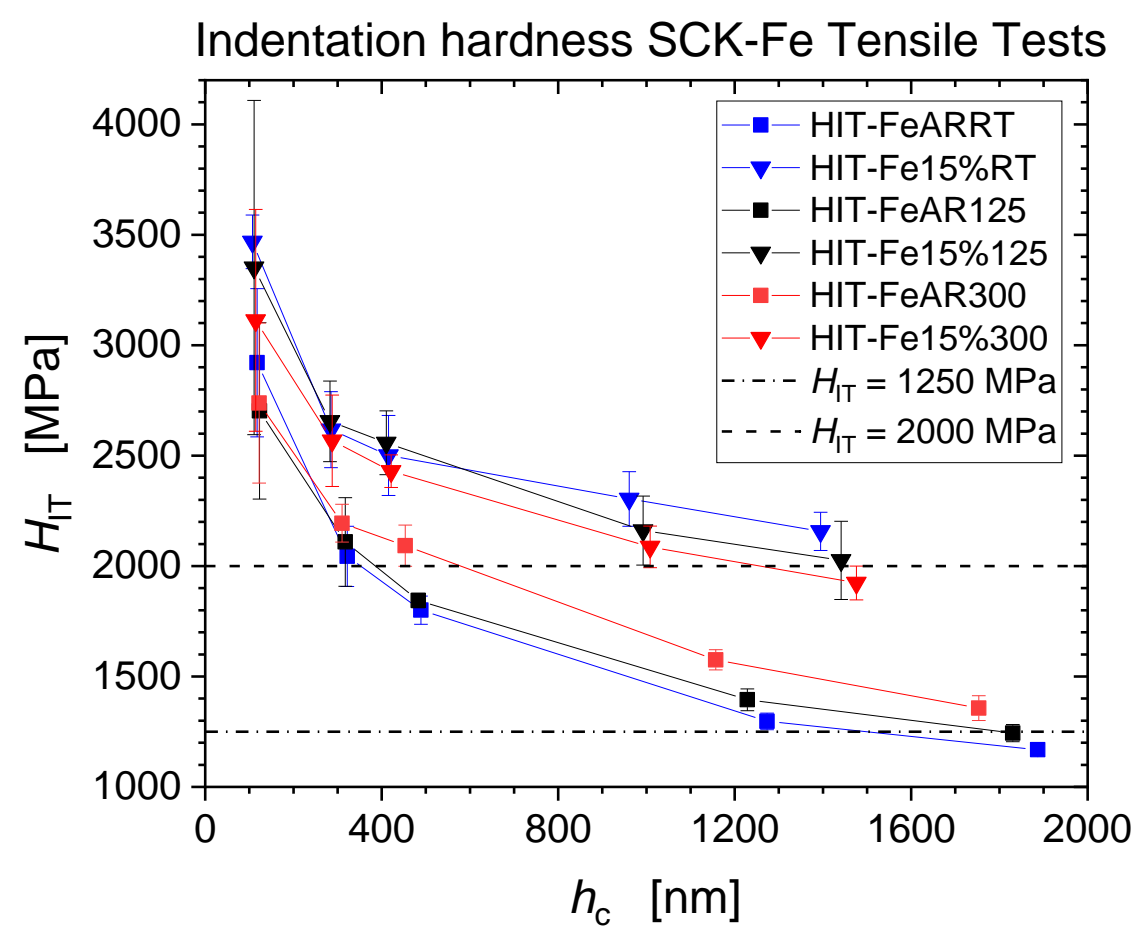

Figure 3. Depth dependence of hardness of un-strained and 15\% pre-strained Fe from nanoindentation measurements.

The measured data were analysed according to ISO-14577 by fitting the $98 \%$ to $40 \%$ $F_{\max }$ portion of the unloading curve to a power law and using the fitted parameters to calculate the contact depth $h_{\mathrm{c}}$ and stiffness $S$. Indentation hardness $H_{\mathrm{IT}}$ and reduced modulus of the contact $E_{\mathrm{r}}$ are then determined by the calibrated projected area of the contact between the indenter and the sample $A_{\mathrm{p}}$ :

$$
\begin{gathered}
H_{\mathrm{IT}}=\frac{F_{\max }}{A_{\mathrm{p}}\left(h_{\mathrm{c}}\right)} \\
E_{\mathrm{r}}=\frac{\sqrt{\pi} S}{2 \beta \sqrt{A_{\mathrm{p}}\left(h_{\mathrm{c}}\right)}}
\end{gathered}
$$

where $\beta$ is a geometric factor, which amounts to 1.034 for a Berkovich indenter. The indentation modulus relates to the reduced modulus according to

$$
E_{\mathrm{IT}}=\frac{1-v_{\mathrm{s}}^{2}}{\frac{1}{E_{\mathrm{r}}}-\frac{1-v_{\mathrm{i}}^{2}}{E_{\mathrm{i}}}}
$$

with Poisson ratios of the Fe samples and the diamond indenter $v_{\mathrm{s}}=0.3$ and $v_{\mathrm{i}}=0.07$, respectively, and $E_{\mathrm{i}}=1141 \mathrm{GPa}$ for the elastic modulus of the indenter.

After the nanoindentation tests, indents were imaged by AFM with a Nanosurf, Switzerland equipped with pyramidal silicon ACLA tip, for non-contact tapping mode, and using dynamic force mode.

\section{Results and Discussion}

\subsection{Hardness and Young's Modulus from Nanoindentation}

Figures 3 and 4 present the experimental results of the averaged indentation hardness $\left(H_{\mathrm{IT}}\right)$ and the indentation elastic modulus $\left(E_{\mathrm{IT}}\right)$ from the force-controlled nanoindentation measurements at the five force levels $F_{\max }=\{1 ; 5 ; 10 ; 50 ; 100\} \mathrm{mN}$ for the as received, and the pre-strained iron. Error bars correspond to the standard deviations from the 10 repeat 
measurements for each condition. A pronounced indentation size effect (ISE) is visible for all specimens $[6,7,12]$. As one compares the data from as-received and pre-strained Fe for the three tensile deformation temperatures $\mathrm{RT}, 125^{\circ} \mathrm{C}$ and $300{ }^{\circ} \mathrm{C}$, one observes that the pre-strained conditions level out at micro-hardness values of about $2000 \mathrm{MPa}$, significantly higher than the as-received conditions at about $1250 \mathrm{MPa}$. Indentation modulus values do not show significant depth dependence but exhibit larger levels of scatter as compared to hardness values ranging from $\sim 190 \mathrm{GPa}$ to $240 \mathrm{GPa}$ for the as-received material, while moduli tend to increase for the pre-strained conditions ranging from $\sim 250 \mathrm{GPa}$ up to 300 GPa. This is an indication for increased disposition for pile-up formation following pre-straining of the material [8].

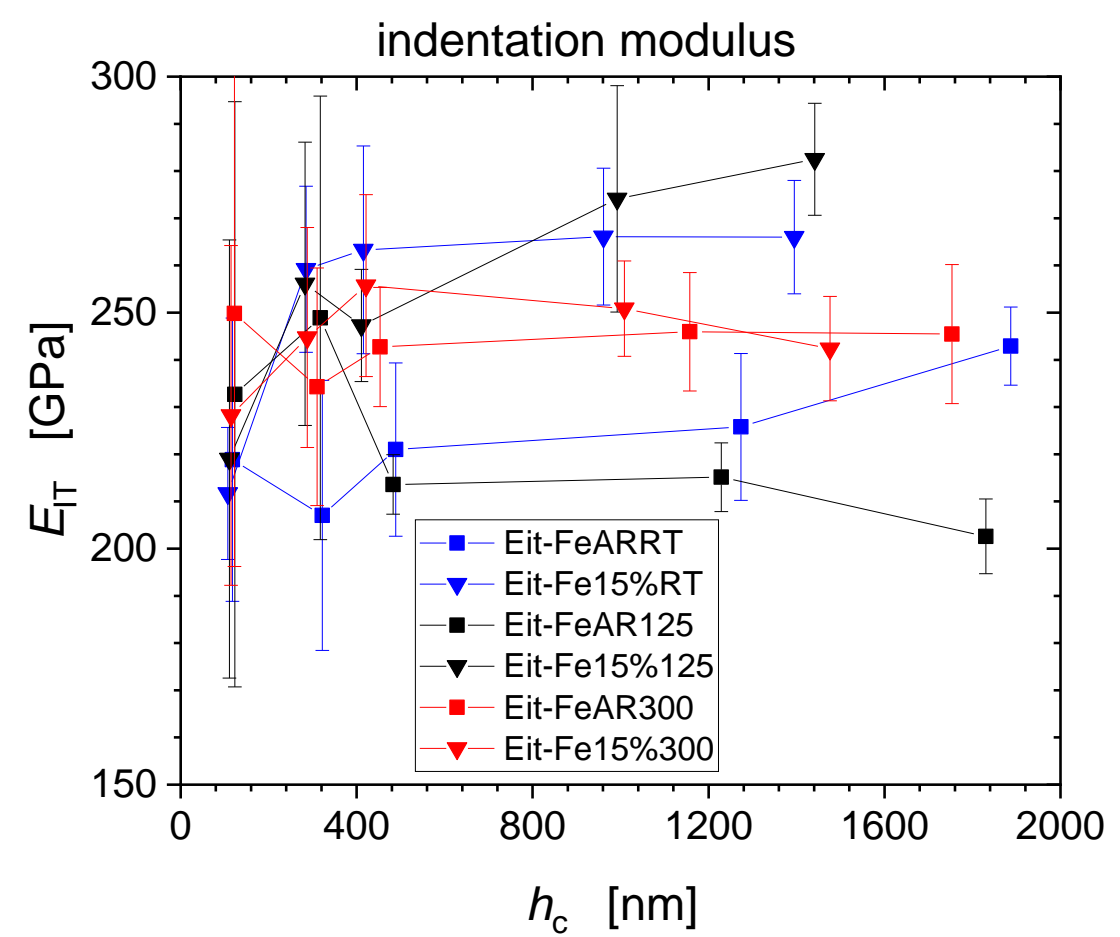

Figure 4. Indentation modulus values of un-strained and $15 \%$ pre-strained Fe as measured by nanoindentation.

The appearance and morphology of pile-ups depend on the work hardening of the material [20]. The hardness is inversely proportional to the contact area and the Young's modulus is inversely proportional to the square root of the contact area [21]. Since the Oliver-Pharr method used for evaluation is based on the contact area as calibrated with respect to the plane of the original surface, rather than the actual contact area receiving the load $[8,22,23]$, the contact area is underestimated in the presence of the pile-up formation causing the values of hardness and reduced modulus to be overestimated.

\subsection{Pile-Up Effect on the Mechanical Properties}

Significant pile-up behaviour as anticipated from nanoindentation results has been confirmed by AFM measurements. Figure 5 presents AFM images $(25 \mu \mathrm{m} \times 25 \mu \mathrm{m}) \mathrm{ob}-$ tained from as-received and pre-deformed Fe samples after nanoindentation with $100 \mathrm{mN}$ force. To quantify the developed pile-ups, cross-section profiles corresponding to the AFM images obtained from the lines crossing the three distinct sides of the indentation edges have been determined (Figure 6). Due to the geometry of the Berkovich indenter, the pile-up heights at the corners of the triangular impression are small as compared to those adjacent to the side edges. For each indent, three cross-sectional profiles have been acquired and pile-up heights measured as the difference in height between the material upheaval peak and the original sample surface ahead of each corner or side [23]. 


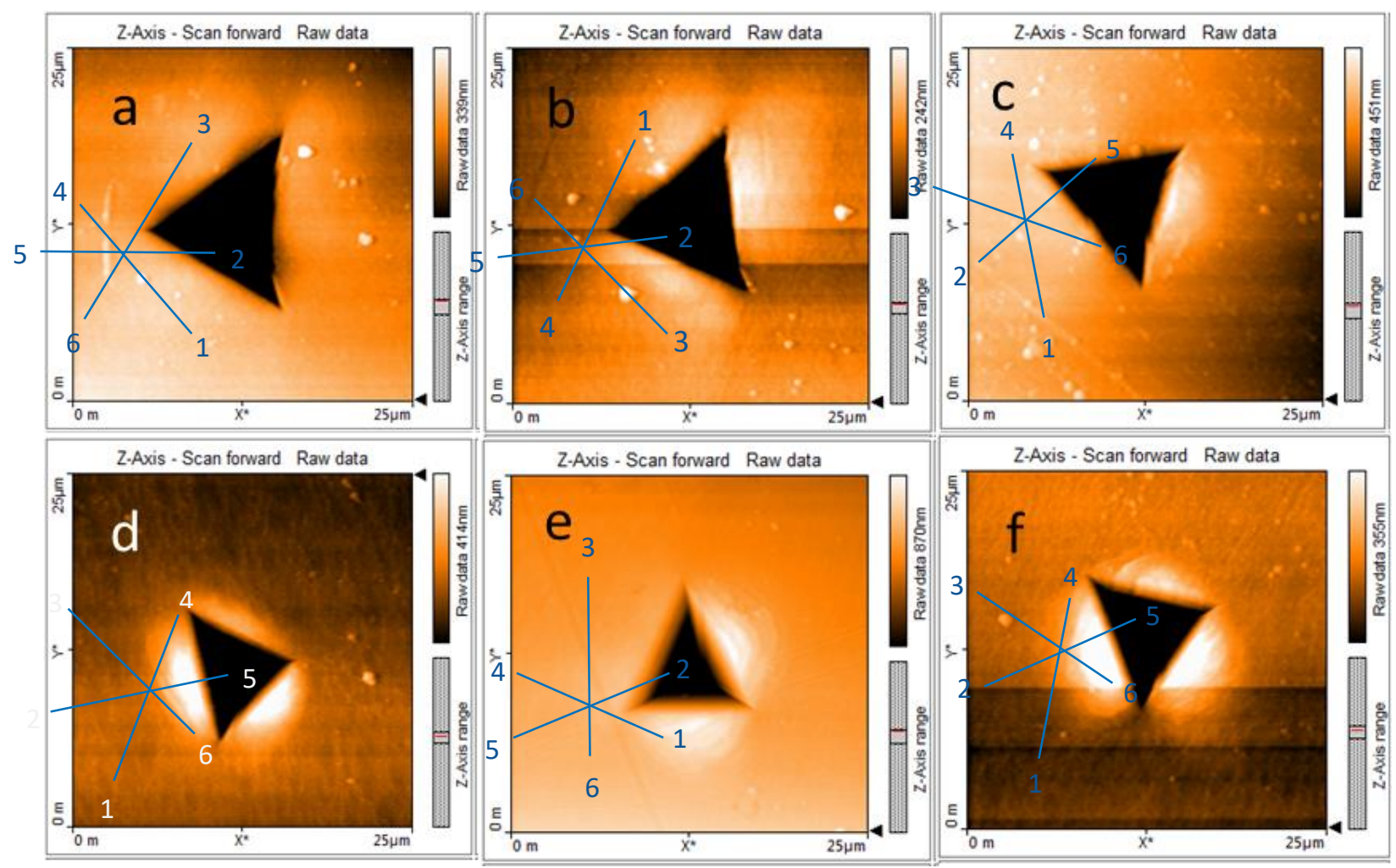

Figure 5. AFM images of Fe after nanoindentation: (a) Fe-AR-RT, (b) Fe-AR- $125^{\circ} \mathrm{C}$, (c) Fe-AR-300 ${ }^{\circ} \mathrm{C},(\mathbf{d}) \mathrm{Fe}-15 \%-\mathrm{RT}$, (e) $\mathrm{Fe}-15 \%-125^{\circ} \mathrm{C}$, (f) Fe- $15 \%-300{ }^{\circ} \mathrm{C}$, with the directions numbered as shown for the depth profiles of Figure 6.

Figure 7 reveal the relation between hardness and pile-up height, respectively, as a function of tensile test temperature, and the effect that the pre-deformation has on it. The pile-up heights from room temperature indentation for the non-deformed states increase with increasing tensile pre-deformation temperature, i.e., ageing temperature, unlike what holds for the pre-deformed state of the material, where the hardness and the pile-up heights decrease with increasing tensile test temperature, i.e., pre-deformation temperature. The temperature and pre-deformation dependence of the hardness are closely associated with the pile-up height. The increased propensity for pile-up formation of the pre-deformed state is attributed to a lower strain hardening rate of the plastically pre-deformed material [8].

\subsection{Relation between Mechanical Properties from Tensile Tests and Hardness Measurements}

Self-similar pyramidal indenters like Berkovich indenters induce plastic deformation already for the smallest loads when tip blunting is disregarded. Therefore, yielding as the onset of plastic deformation of the material is not as straightforward to access as in the analysis of a tensile test. A geometrically perfect self-similar Berkovich indenter is more properly associated with a finite representative strain.

Tabor has argued that the tensile strength of a material affects its hardness, which relates to the flow stress via a constraint factor of about three [11]:

$$
H_{\text {Tabor }} \approx 3 \sigma
$$

For a material undergoing strain hardening a characteristic stress must be chosen, which can be approximated by the flow stress at a representative strain level of $8 \%: H_{\text {Tabor }}=3 \sigma(\epsilon=8 \%)$. This implies neglecting the ISE and identifying $H_{\text {Tabor }}$ with the micro-hardness level $H_{0}$ approached for the largest nanoindentation depths (here at $F_{\max }=100 \mathrm{mN}$ ). 

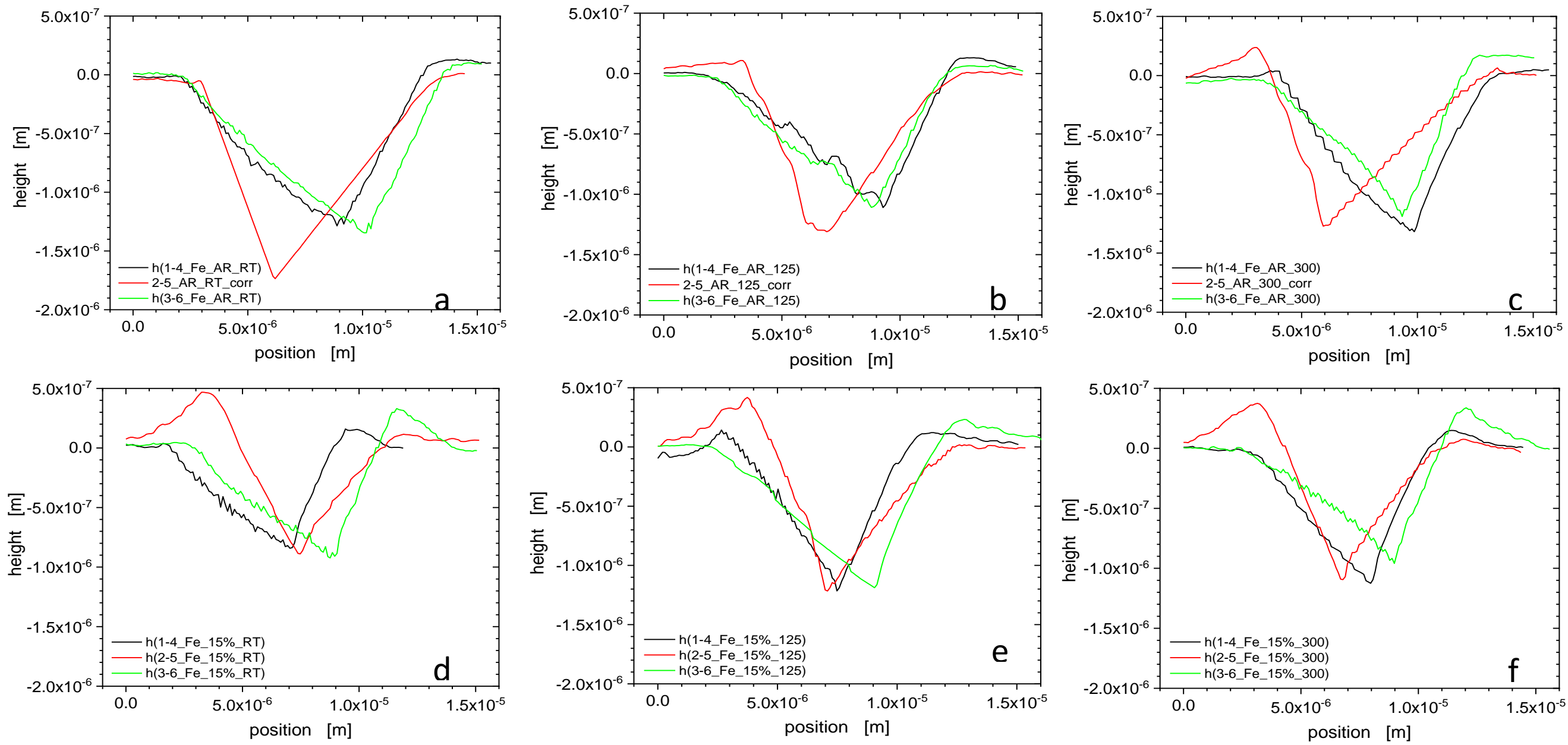

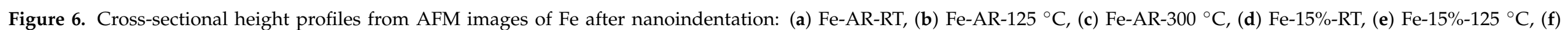

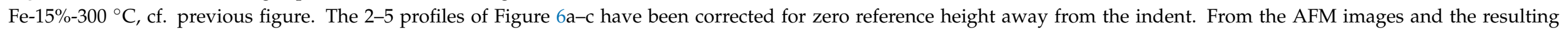

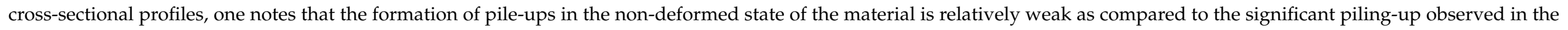
pre-deformed state of the material. Pre-deformation enhances the pile-up propensity, which affects the apparent nanoindentation hardness. 


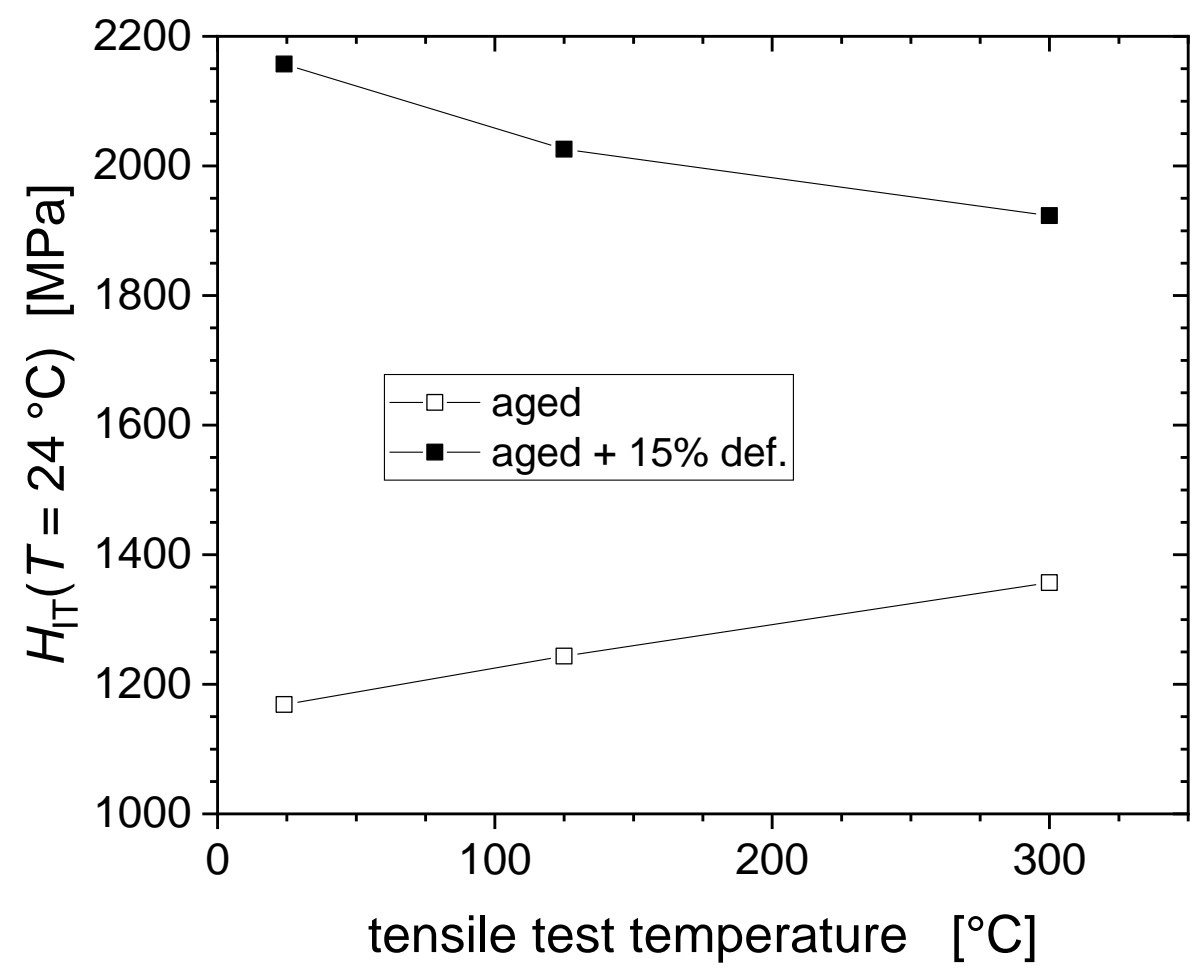

(a)

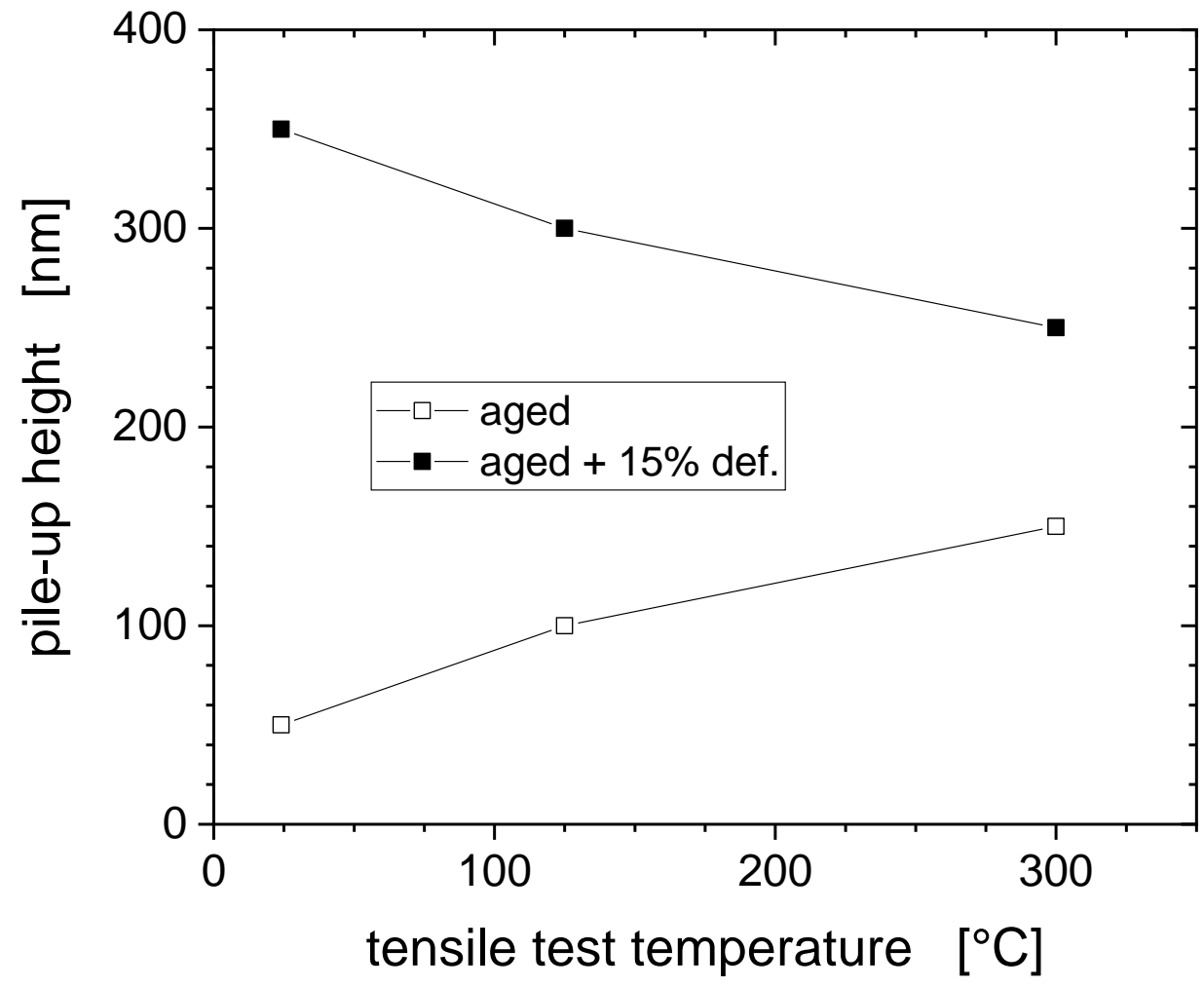

(b)

Figure 7. Correlation between the indentation hardness measured at RT and the tensile test temperature (a), and between pile-up effect and tensile test temperature (b). 
Table 4 presents tensile test data in terms of the yield stress, the ultimate tensile strength and the final strength of the material, alongside the hardness predicted from the final strength, according to Tabor's Equation (4). Here the final strength is defined as the force at rupture divided by the rupture cross-section as measured after the test. As shown in Figure 3 the average hardness at $100 \mathrm{mN}$ for the as-received conditions is $1250 \mathrm{MPa}$ and $\sim 2000 \mathrm{MPa}$ for the pre-strained conditions, whereas Tabor's prediction from $\sigma_{\text {FS }}$ would result in average hardness at $100 \mathrm{mN}$ of $\sim 738 \mathrm{MPa}$ for as-received, and $\sim 1089 \mathrm{MPa}$ for pre-strained iron, i.e., much lower values by almost a factor of two. This significant and systematic mismatch between the actually measured and the predicted hardness values is attributed to the pronounced pile-up formation during indentation [21,22]. This is even more significant if one notes that the Hall-Petch contribution to the flow stress (affecting tensile strength but not hardness) was not taken into account, when the predicted strength was calculated [13]. There is also a strong discrepancy of the apparent hardness increase due to pre-straining of about $750 \mathrm{MPa}$ on the one hand, and Tabor's prediction of the hardness increase of $3 \Delta \sigma=3\left(\sigma_{\mathrm{FS}}-\sigma_{\mathrm{y}}\right)$ which amounts to approx. only 300 to $670 \mathrm{MPa}[11]$.

Table 4. Tensile properties from tensile pre-deformation tests and corresponding hardness according to Tabor's predictions.

\begin{tabular}{|c|c|c|c|c|c|c|}
\hline $\begin{array}{c}\text { Deformation } \\
\text { Temperature } \\
\qquad\left[{ }^{\circ} \mathrm{C}\right]\end{array}$ & $\begin{array}{c}\text { Upper Yield } \\
\text { Stress } \\
\text { [MPa] }\end{array}$ & $\begin{array}{c}\text { Lower Yield } \\
\text { Stress } \sigma_{\mathbf{y}} \\
\text { [MPa] }\end{array}$ & $\begin{array}{c}\text { Ultimate } \\
\text { Tensile } \\
\text { Strength } \\
\text { [MPa] }\end{array}$ & $\begin{array}{c}\text { Final Strength } \\
\sigma_{\mathrm{FS}} \\
{[\mathrm{MPa}]}\end{array}$ & $\begin{array}{c}3 \sigma_{\mathrm{FS}} \\
{[\mathrm{MPa}]}\end{array}$ & $\begin{array}{c}\Delta \sigma= \\
\left(\sigma_{\mathrm{FS}}-\sigma_{\mathrm{y}}\right) \\
{[\mathrm{MPa}]}\end{array}$ \\
\hline 24 (RT) & 145 & 125 & 226 & 246 & 738 & 101 \\
\hline 125 & 115 & 103 & 325 & 363 & 1089 & 222 \\
\hline 300 & \multicolumn{2}{|c|}{82} & 276 & 304 & 912 & 194 \\
\hline
\end{tabular}

\subsection{Elastic Modulus Correction}

The indentation hardness results observed for unalloyed Fe exhibit a large systematic mismatch with the tensile data that affects both absolute strength and strength increase due to strain hardening (Figures 2 and 3, and Table 4). The cause for this discrepancy does not imply inadequacy of the underlying Tabor constraint relation (4) in the first place, but can be attributed to the pronounced pile-up emergence, in particular, after pre-straining. This has been confirmed by AFM (Figures 5 and 6). The mismatch between observed and predicted strength data can largely be reconciled by the application of an elastic modulus correction (EMC) procedure [24].

Assuming for the reduced plane strain modulus a reference value $E_{\mathrm{r}, \mathrm{ref}}=183 \mathrm{GPa}$,

$$
\frac{1}{E_{\mathrm{r}, \mathrm{ref}}}=\frac{1-v_{\mathrm{s}}^{2}}{E_{\mathrm{s}}}+\frac{1-v_{\mathrm{i}}^{2}}{E_{\mathrm{i}}}
$$

which is calculated using tensile data for a Young's modulus $E_{\mathrm{s}}=200 \mathrm{GPa}$ and $v_{\mathrm{s}}=0.3$, instead of $E_{\mathrm{IT}}$, Equation (3) from nanoindentation, and taking into account Equations (1) and (2) any micro-hardness bias deriving from systematic errors in the area function can be corrected by:

$$
H_{0, \text { corr }}=\frac{H_{0}}{\left(\frac{E_{\mathrm{r}}\left(h_{\mathrm{c}}\right)}{E_{\mathrm{r}, \mathrm{ref}}}\right)^{2}}
$$

Figure 8 shows the reduced elastic modulus of the material corresponding to the indentation moduli presented previously in Figure 4. By definition, reduced modulus values are lower as compared to the indentation modulus, and range for the as-received material from $\sim 190 \mathrm{GPa}$ to $\sim 220 \mathrm{GPa}$ and for the pre-strained conditions from $\sim 220 \mathrm{GPa}$ up to $\sim 250 \mathrm{GPa}$. 


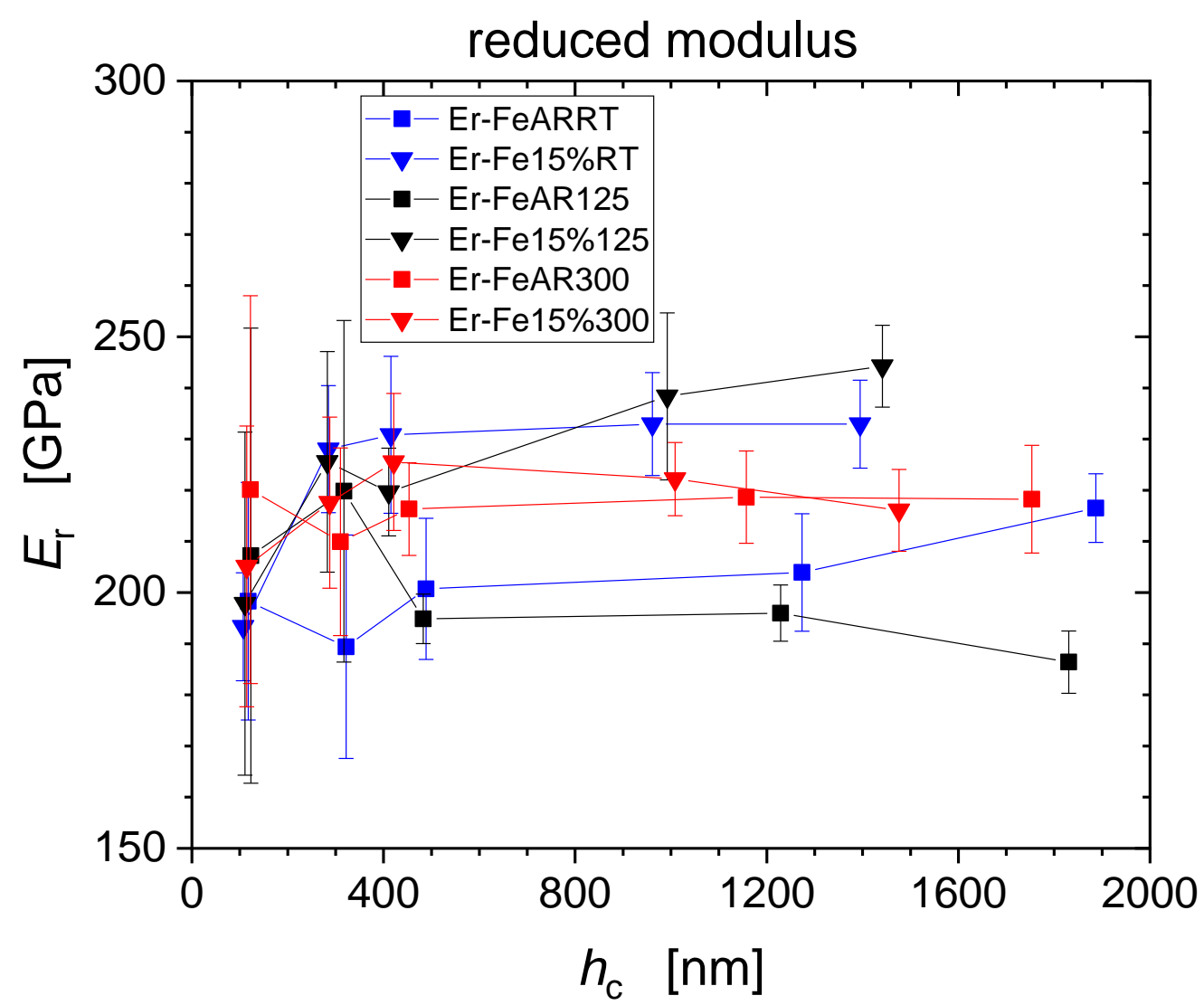

Figure 8. Reduced modulus values obtained from nanoindentation measurements and used for EMC procedure.

Table 5 compiles average reduced modulus values obtained from averaging the moduli for the three largest force levels $10 \mathrm{mN} ; 50 \mathrm{mN}$; $100 \mathrm{mN}$. These values have been used for the definition of common elastic modulus correction factors of each testing condition of the material.

Table 5. Averaged reduced modulus for $10 \mathrm{mN} ; 50 \mathrm{mN}$ and $100 \mathrm{mN}$ force, as used for EMC.

\begin{tabular}{|c|c|c|c|c|}
\hline Condition & $\begin{array}{c}\text { Reduced } \\
\text { Modulus at } 10 \\
\text { mN } \\
{[\text { GPa] }}\end{array}$ & $\begin{array}{c}\text { Reduced } \\
\text { Modulus at } 50 \\
\text { mN } \\
{[\mathrm{GPa}]}\end{array}$ & $\begin{array}{c}\text { Reduced } \\
\text { Modulus at } 100 \\
\text { mN } \\
{[\mathrm{GPa}]}\end{array}$ & $\begin{array}{c}\text { Average } \\
\text { Reduced } \\
\text { Modulus } \\
\text { [GPa] }\end{array}$ \\
\hline $24^{\circ} \mathrm{C}$ AR & 201 & 204 & 216 & 207 \\
\hline $24^{\circ} \mathrm{C} 15 \%$ & 231 & 233 & 233 & 232 \\
\hline $125^{\circ} \mathrm{C} \mathrm{AR}$ & 195 & 196 & 186 & 192 \\
\hline $125^{\circ} \mathrm{C} 15 \%$ & 220 & 238 & 244 & 234 \\
\hline $300^{\circ} \mathrm{C}$ AR & 216 & 219 & 218 & 218 \\
\hline $300^{\circ} \mathrm{C} 15 \%$ & 226 & 222 & 216 & 221 \\
\hline
\end{tabular}

The hardness values after application of the EMC procedure are presented in Figure 9 showing that now micro-hardness values level out at about $1000 \mathrm{MPa}$ and $1300 \mathrm{MPa}$ for the as-received conditions and pre-strained conditions, which is to be compared to the original apparent hardness levels amounting to $1250 \mathrm{MPa}$ and $2000 \mathrm{MPa}$, respectively. In particular, we note that the EMC procedure results in a much smaller hardness difference between the as-received and pre-deformed materials conditions ( 300 MPa), in closer correspondence with Tabor's prediction (Table 4). 


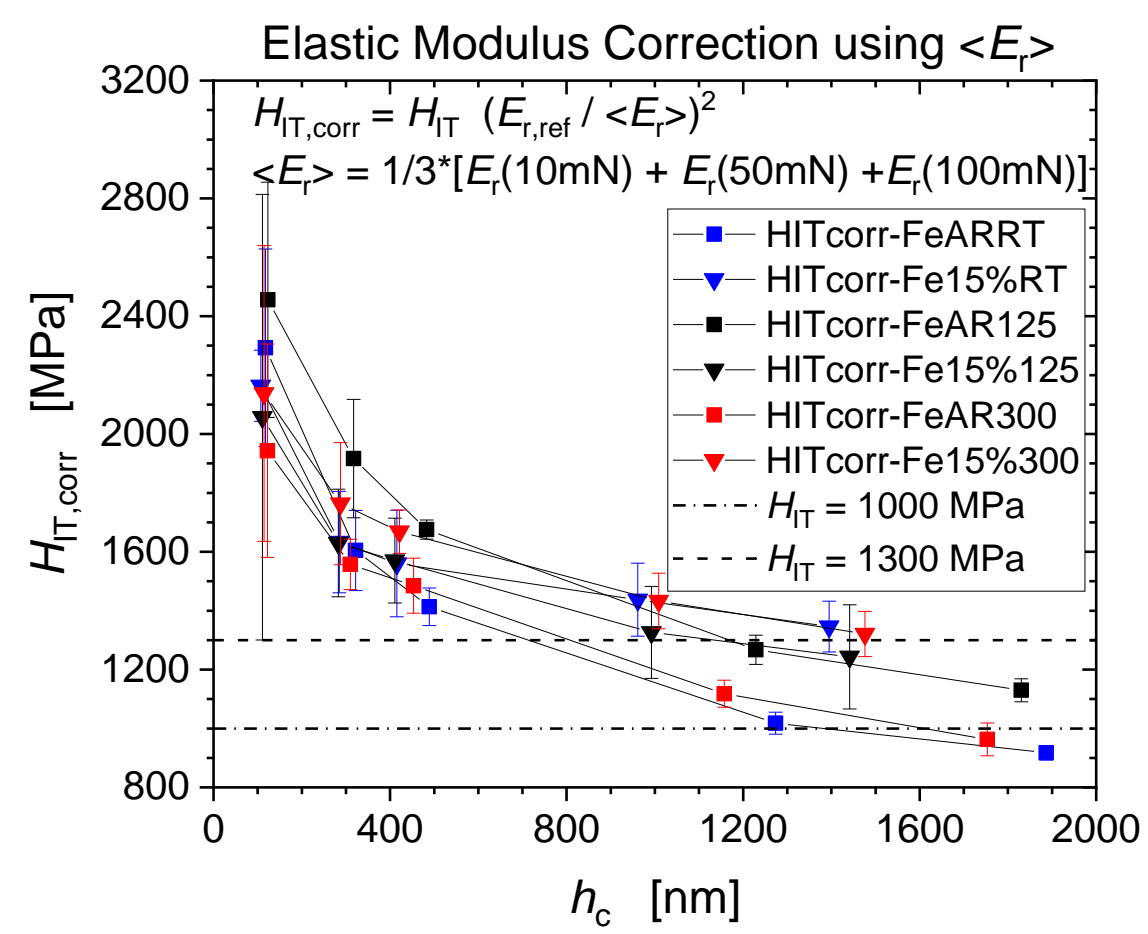

Figure 9. Corrected indentation hardness of un-strained and $15 \%$ pre-strained Fe.

Figure 10 demonstrates an inverse temperature dependence of the strength, both in terms of hardness and final tensile strength, the origin of which is discussed in the following subsection. After application of the EMC a reasonable agreement between hardness and tensile strength values has been accomplished, with the corrected hardness values being again much closer to the strength predicted by Tabor's Equation (4).

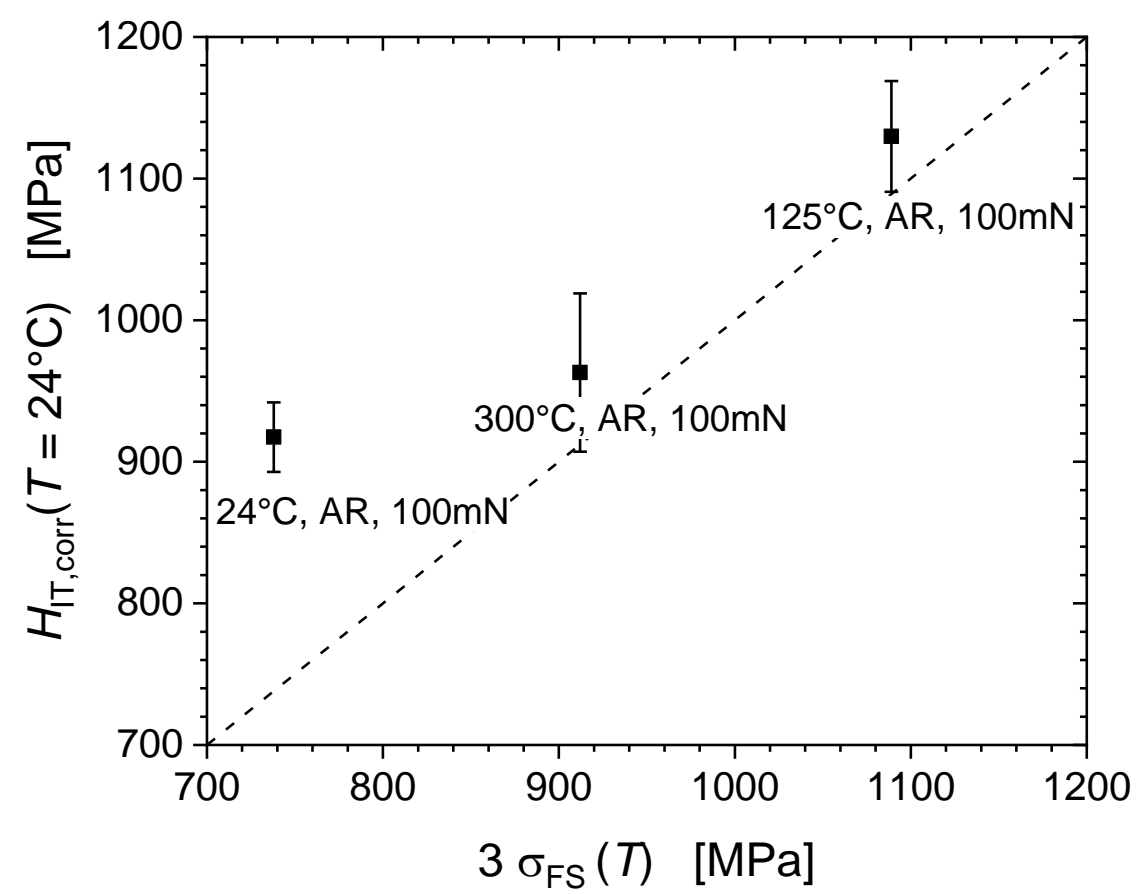

Figure 10. Hardness vs. tensile strength correlation after EMC.

\subsection{Dynamic Strain Ageing (DSA) Effect on Strain Hardening}

Figure 9 shows that strain hardening due to tensile pre-deformation is captured by the EMC corrected hardness measurements. The microhardness observed at the largest 
depths amounts to $1300 \mathrm{MPa}$ vs. $\sim 1000 \mathrm{MPa}$ in the as-received condition. The ISE is similarly pronounced for both conditions. Hardness differences are mainly due to dislocation multiplication induced during plastic pre-deformation and described by the Taylor contribution to the flow stress associated with forest hardening:

$$
\sigma_{f}=\widetilde{\alpha} \mu b \sqrt{\rho}
$$

where $\mu$ denotes the shear modulus, $b$ the magnitude of the Burgers vector, $\rho$ the dislocation density, and $\widetilde{\alpha}=M \alpha$ a numerical coefficient which contains a factor $\alpha \approx 0.3$ and the Taylor factor $M \approx 3$ and which is assumed to amount to 0.9 .

Table 6 compiles the dislocation densities determined from TEM analysis and the corresponding Taylor stresses from Equation (7), as compared to the work hardening presented in Table 4, alongside the hardness increase (corrected by EMC). The hardness increase is more pronounced for the lower pre-straining temperature, as less dynamic recovery is occurring during plastic deformation. At low temperatures, mobile dislocations interact with quasi-sessile carbon impurities in interstitial solution with the otherwise high purity iron giving rise to additional solid solution strengthening of the material [25].

Table 6. Dislocation densities from TEM observations and Taylor stresses from the corresponding dislocation forests, as compared to the work hardening (Table 4) and hardness increase (corrected by EMC).

\begin{tabular}{ccccc}
\hline $\begin{array}{c}\text { Deformation } \\
\text { Temperature } \\
{\left[{ }^{\circ} \mathrm{C}\right]}\end{array}$ & $\begin{array}{c}\boldsymbol{\rho} \\
{\left[\mathbf{1 0}^{\mathbf{1 4}} \mathbf{m}^{-\mathbf{2}}\right]}\end{array}$ & $\begin{array}{c}\sigma_{f}=\tilde{\alpha} \mu b \sqrt{\rho} \\
{[\mathbf{M P a}]}\end{array}$ & $\begin{array}{c}\sigma_{f}-\boldsymbol{\Delta} \boldsymbol{\sigma} \\
{[\mathbf{M P a}]}\end{array}$ & $\begin{array}{c}\Delta \boldsymbol{H}_{\text {corr }} / \mathbf{3} \\
{[\mathbf{M P a}]}\end{array}$ \\
\hline $24(\mathrm{RT})$ & 2 & 255 & 134 & 143 \\
\hline 125 & 3.7 & 346 & 86 & 38 \\
\hline 300 & 0.8 & 161 & -61 & 119 \\
\hline
\end{tabular}

The Fe-AR-125 ${ }^{\circ} \mathrm{C}$ aged (not deformed) material appears to be the hardest one, the increase of the corrected hardness being smallest, as during thermal ageing at the intermediate temperature of $125^{\circ} \mathrm{C}$ dislocation cores can saturate with those carbon interstitials [15]. $H_{\text {IT,corr }} \sim 1357 \mathrm{MPa}$ at $125^{\circ} \mathrm{C}$ represents the highest hardness value reported in Figure 10. At this intermediate temperature, dynamic strain ageing (DSA) occurs by the dynamic interaction of mobile dislocations and carbon interstitial atoms, noting that $C$ concentration well below the present detection limit of about $300 \mathrm{ppm}$ are sufficient to induce DSA [15]. DSA is associated with serrated flow (Portevin-Le Chatelier effect) which is clearly visible on the $125^{\circ} \mathrm{C}$ tensile stress-strain curve in Figure 11. In body-centred-cubic (bcc) iron, DSA and serrated flow are associated with the so-called "blue-brittleness" temperature range of 100 to $300{ }^{\circ} \mathrm{C}$ [26-29]. The concomitant plastic instability and strain localization cause the hardness spread to increase most significantly through pre-deformation at the intermediate temperature of $125^{\circ} \mathrm{C}$, as illustrated by Figures 2 and 3 .

The tensile tests at RT and $125^{\circ} \mathrm{C}$ also reveal yield phenomena at the onset of plastic deformation, i.e., inhomogeneous deformation (localized flow) through propagation of a Lüders band upon unpinning of the dislocations from their saturated solute clouds. The absence of serrated yielding and Lüders band formation for $300{ }^{\circ} \mathrm{C}$ shows that for the highest tensile deformation temperature the ageing does not matter as the solute atoms are sufficiently mobile to diffuse together with moving dislocations not letting their detachments to occur.

With respect to the hardening behaviour, we note that the flow stress and the strain hardening rate are both maximal at the intermediate temperature of $125^{\circ} \mathrm{C}$ (Figures 11 and 12) [15]. This is also reflected by a maximum of the hardening exponent $\left(n=0.334\right.$ for $\left.125^{\circ} \mathrm{C}\right)$, as indicated in the legend of Figure 11. These results are consistent with the microstructural observations and dislocation analyses reported for the different deformation temperatures. 
Dislocations appear to be heterogeneously distributed with regions of high density with pile-ups and tangles, separated by regions of low dislocation density $\left(\right.$ of $\left.10^{12} \mathrm{~m}^{-2}\right)$, which is comparable to the dislocation density in the non-deformed material. The highest dislocation density of $3.7 \times 10^{14} \mathrm{~m}^{-2}$ was obtained at the deformation temperature of $125^{\circ} \mathrm{C}$, exceeding those at $\mathrm{RT}$ and $300{ }^{\circ} \mathrm{C}$ by factors of about two and four, respectively.

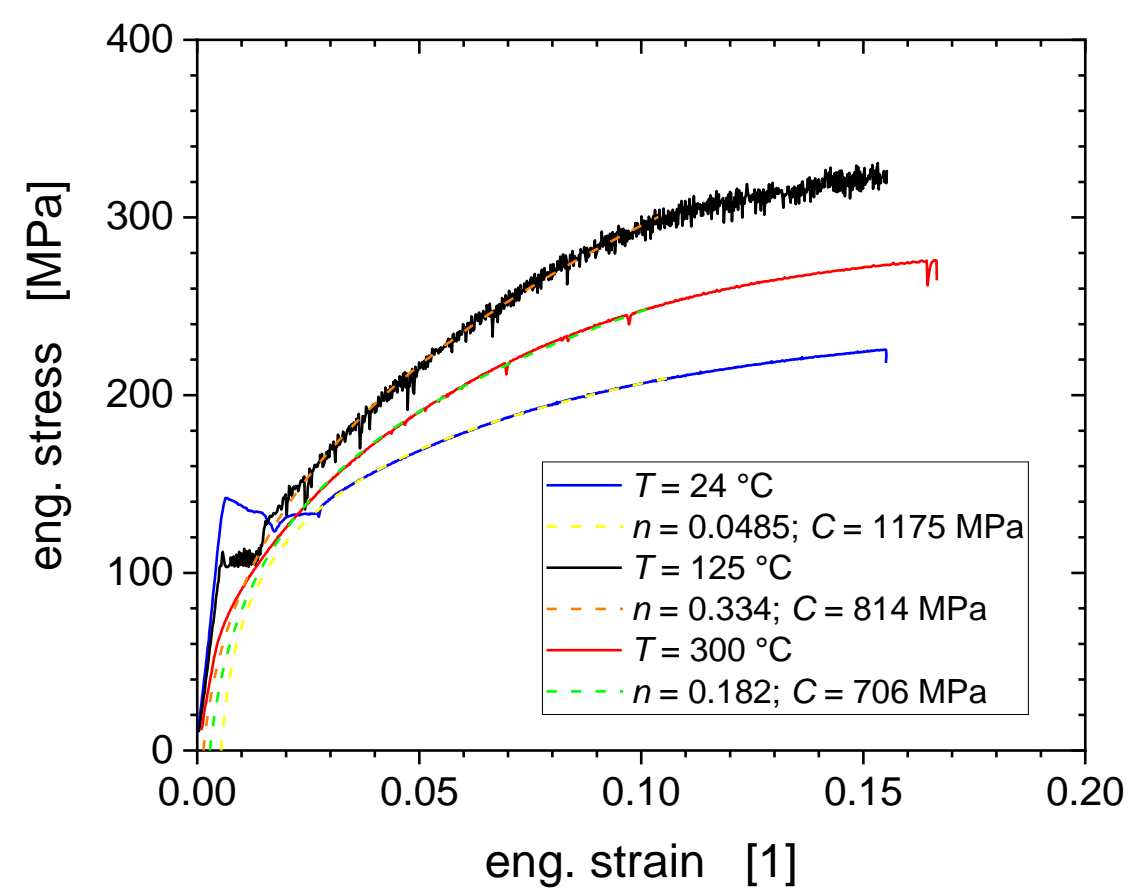

Figure 11. Stress-strain curves from tensile tests exhibiting serrated yielding at $125^{\circ} \mathrm{C}$ and Lüders band propagation at RT and $125^{\circ} \mathrm{C}$. The dashed curves represent power law hardening rules $\sigma=$ $C\left(\varepsilon-\varepsilon_{0}\right)^{n}$ with hardening exponents $n$, strength coefficients $C$, and offset strains $\varepsilon_{0}$ as reported in the legend.

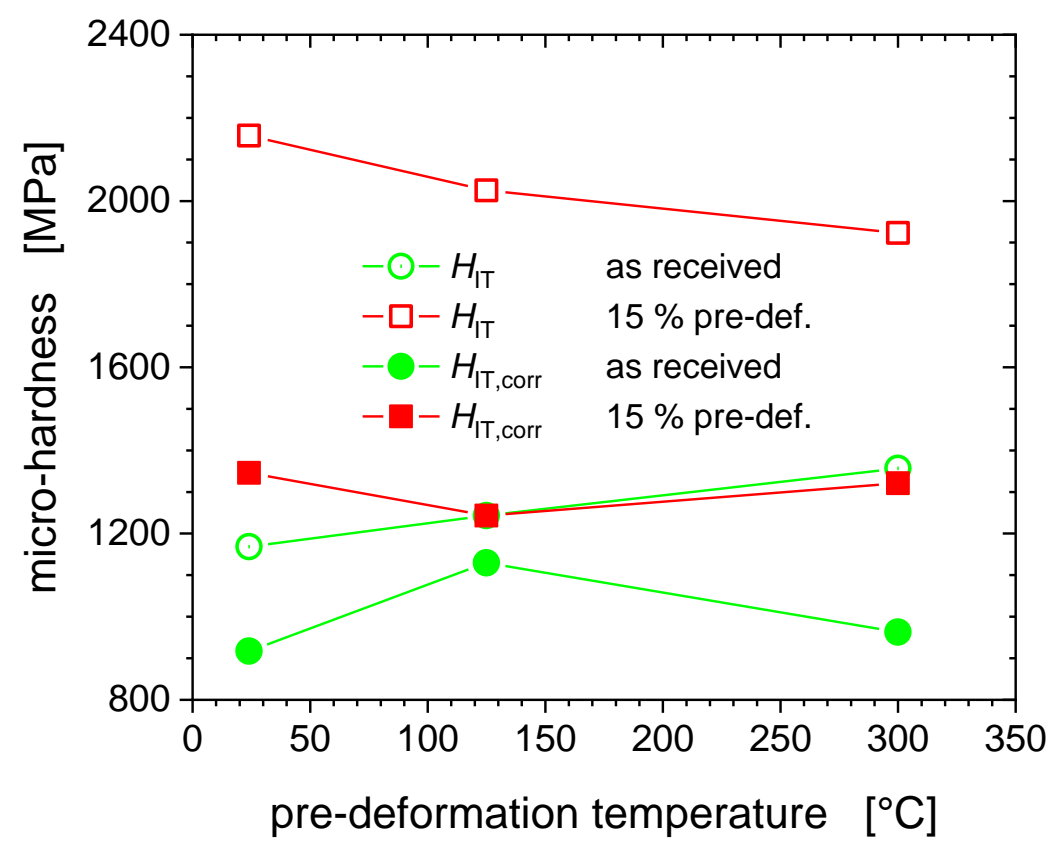

Figure 12. Hardness as a function of the pre-deformation temperature. 
As regards the pre-deformed materials Fe- $15 \%-125^{\circ} \mathrm{C}$ (Figure 9 ) we observed $H_{\text {IT,corr }}$ to exceed by only $\sim 100 \mathrm{MPa}$ the non-deformed reference level at this temperature, i.e., the lowest increase of the three cases $\left(24{ }^{\circ} \mathrm{C}: \Delta H_{\mathrm{IT} \text {, corr }} \sim 430 \mathrm{MPa} ; 300{ }^{\circ} \mathrm{C}: \Delta H_{\mathrm{IT} \text {,corr }} \sim 360 \mathrm{MPa}\right)$. The hardening potential is the lowest for $125^{\circ} \mathrm{C}$, as the material has already hardened significantly and dislocation density is saturated, and therefore their multiplication is rendered difficult [13].

The additional hardening associated with $15 \%$ pre-deformation and observed by the EMC corrected $H_{\mathrm{IT} \text {,corr }}$ at room temperature, possesses a minimum value for the intermediate pre-deformation temperature $T=125^{\circ} \mathrm{C}$, when DSA is most pronounced as shown in Figure 11. The efficient DSA at this intermediate temperature leads to reduced dynamic recovery and enhanced multiplication and accumulation of dislocations. Consequently, the work hardening rate during the tensile test is largest at $125^{\circ} \mathrm{C}$ with $n=0.334$ (Figure 11).

\section{Conclusions}

Hardness data from nanoindentation tests of unalloyed iron have been compared with bulk mechanical properties from tensile testing to $15 \%$ of strain performed at room temperature, $125^{\circ} \mathrm{C}$ and $300{ }^{\circ} \mathrm{C}$. The nanoindentation was carried out on reference and prestrained material. A significant mismatch between the nanohardness and the tensile test results has been observed, attributed to the pile-up formation and subsequently required the nanoindentation results to be corrected accordingly. This has been accomplished by applying an elastic modulus correction (EMC). While in recent previous work the EMC served the correction of various sources of biases of data from multiple sources (round robin testing) [24], here it was specifically performed to account for changes in pile-up height induced by pre-deformation.

In doing so this work has improved our understanding of the way how nanoindentation testing can be used for mechanical property assessment in the presence of the intensive pile-up formation. Pronounced pile-up emergence, which became even more noticeable after the tensile pre-straining, was confirmed by AFM as cause of the large and systematic mismatch between the hardness data and values of the yield stress, the ultimate tensile strength and the final strength of the material as predicted by Tabor's equation on the other hand. Consequently, it turned out to be possible to reconcile the difference between nanomechanical and bulk properties of unalloyed Fe by the elastic modulus correction. The EMC proved an effective alternative to correcting pile-up behaviour by AFM measurements of actual pile-up heights. At the same time, it is much less demanding.

Strain hardening behaviour and nanoindentation hardness results were found to be affected by the dynamic strain ageing (DSA) due to the presence of mobile C interstitials. The results evidence that the material aged at $125^{\circ} \mathrm{C}$ is the hardest, as during thermal ageing dislocation lines saturate with interstitial carbon atoms with the consequence that the corrected hardness has a maximum at this temperature. This is also the reason why tensile tests reveal inhomogeneous deformation through a yield phenomenon (localized flow through propagation of a Lüders bands) and serrated flow due to dynamic strain ageing at the intermediate pre-deformation temperature of $125^{\circ} \mathrm{C}$.

Author Contributions: L.V.: formal analysis, investigation, writing-original draft. P.H.: conceptualization, methodology, formal analysis, investigation, writing-original draft. A.D.: investigation. T.K.: investigation. D.T.: conceptualization, methodology, writing-review and editing. A.R.-M.: formal analysis, investigation, writing - review and editing. All authors have read and agreed to the published version of the manuscript.

Funding: This research received funding from the Euratom research and training programme 20142020 under grant agreement No. 755,039 (M4F project) and has been supported by the EURATOM Direct Actions of the European Commission's Joint Research Centre.

Institutional Review Board Statement: Not applicable.

Informed Consent Statement: Not applicable. 
Data Availability Statement: The data presented in this study are available on request from the corresponding author.

Acknowledgments: This work contributes to the Joint Programme on Nuclear Materials (JPNM) of the European Energy Research Alliance (EERA), in particular to the EERA JPNM pilot project NINANanoIndentation for Nuclear Applications. It has received funding from the Euratom research and training programme 2014-2020 under grant agreement No. 755,039 (M4F project) and has been supported by the EURATOM Direct Actions of the European Commission's Joint Research Centre. The authors gratefully acknowledge the contribution of Hygreeva Namburi from Centrum Vyzkumu Rez (CVR), Czech Republic for his assistance with the preparation of the test specimens.

Conflicts of Interest: The authors declare no conflict of interest.

\section{References}

1. Kositski, R.; Mordehai, D. Depinning-controlled plastic deformation during nanoindentation of BCC iron thin films and nanoparticles. Acta Mater. 2015, 90, 370-379. [CrossRef]

2. De Guzman, M.S.; Neubauer, G.; Flinn, P.A.; Nix, W.D. The Role of Indentation Depth on the Measured Hardness of Materials. MRS Proc. 1993, 308, 613. [CrossRef]

3. Mordehai, D.; Kazakevich, M.; Srolovitz, D.J.; Rabkin, E. Nanoindentation size effect in single-crystal nanoparticles and thin films: A comparative experimental and simulation study. Acta Mater. 2011, 59, 2309-2321. [CrossRef]

4. Bahr, D.; Morris, D.J. Nanoindentation: Localized Probes of Mechanical Behavior of Materials. In Springer Handbook of Systematic Musicology; Sharpe, W., Ed.; Springer: Boston, MA, USA, 2008; pp. 389-408.

5. Leitner, A.; Maier-Kiener, V.; Kiener, D. Dynamic nanoindentation testing: Is there an influence on a material's hardness? Mater Res. Lett. 2017, 5, 486-493. [CrossRef] [PubMed]

6. Durst, K.; Göken, M.; Pharr, G.M. Indentation size effect in spherical and pyramidal indentations. J. Phys. D Appl. Phys. 2008, 41, 074005. [CrossRef]

7. Ruiz-Moreno, A.; Hähner, P. Indentation size effects of ferritic/martensitic steels: A comparative experimental and modelling study. Mater. Des. 2018, 145, 168-180. [CrossRef]

8. Moharrami, N.; Bull, S. A comparison of nanoindentation pile-up in bulk materials and thin films. Thin Solid Films 2014, 572, 189-199. [CrossRef]

9. Liu, M.; Lu, C.; Tieu, K.A.; Zhou, K. Crystal plasticity FEM study of nanoindentation behaviors of $\mathrm{Cu}$ bicrystals and $\mathrm{Cu}-\mathrm{Al}$ bicrystals. J. Mater. Res. 2015, 30, 2485-2499. [CrossRef]

10. Liu, M.; Tieu, A.K.; Peng, C.-T.; Zhou, K. Explore the anisotropic indentation pile-up patterns of single-crystal coppers by crystal plasticity finite element modelling. Mater. Lett. 2015, 161, 227-230. [CrossRef]

11. Tabor, T. The Hardness of Metals; Clarendon Press: Oxford, UK, 1948.

12. Nix, W.D.; Gao, H. Indentation size effects in crystalline materials: A law for strain gradient plasticity. J. Mech. Phys. Solids 1998, 46, 411-425. [CrossRef]

13. Armstrong, R.W. 60 Years of Hall-Petch: Past to Present Nano-Scale Connections. Mater. Trans. 2014, 55, 2-12. [CrossRef]

14. Ren, S.; Mazière, M.; Forest, S.; Morgeneyer, T.F.; Rousselier, G. A constitutive model accounting for strain ageing effects on work-hardening. Application to a C-Mn steel. Comptes Rendus Mécanique 2017, 345, 908-921. [CrossRef]

15. Caillard, D. Dynamic strain ageing in iron alloys: The shielding effect of carbon. Acta Mater. 2016, 112, 273-284. [CrossRef]

16. Terentyev, D.; Xiao, X.; Dubinko, A.; Bakaeva, A.; Duan, H. Dislocation-mediated strain hardening in tungsten: Thermomechanical plasticity theory and experimental validation. J. Mech. Phys. Solids 2015, 85, 1-15. [CrossRef]

17. Hirsch, P.; Howie, A.; Nicholson, R.; Pashley, D.W.; Whelan, M.J. Microscopy of Thin Crystals; Krieger Publishing Company: Malabar, FL, USA, 1977.

18. Dubinko, A.; Terentyev, D.; Bakaeva, A.; Verbeken, K.; Wirtz, M.; Hernández-Mayoral, M. Evolution plastic deformation in heavily deformed and recrystallized tungsten of ITER specification studied by TEM. Int. J. Refract. Mater. 2017, 66, 105-150. [CrossRef]

19. Herrmann, K.; Jennett, N.; Wegener, W.; Meneve, J.; Hasche, K.; Seemann, R. Progress in determination of the area function of indenters used for nanoindentation. Thin Solid Films 2000, 377, 394-400. [CrossRef]

20. Oliver, W.C.; Pharr, G.M. Measurement of hardness and elastic modulus by instrumented indentation: Advances in understanding and refinements to methodology. J. Mater. Res. 2004, 19, 3. [CrossRef]

21. Oliver, W.; Pharr, G. An improved technique for determining hardness and elastic modulus using load and displacement sensing indentation experiments. J. Mater. Res. 1992, 7, 1564-1583. [CrossRef]

22. Bolshakov, A.; Pharr, G.M. Influences of pile-up on the measurement of mechanical properties by load and depth sensing indentation techniques. J. Mater. Res. 1998, 13, 1049. [CrossRef]

23. Kese, K.; Li, Z.C. Semi-ellipse method for accounting for the pile-up contact area during nanoindentation with the Berkovich indenter. Scr. Mater. 2006, 55, 699-702. [CrossRef] 
24. Ruiz-Moreno, A.; Hähner, P.; Kurpaska, L.; Jagielski, J.; Spätig, P.; Trebala, M.; Hannula, S.-P.; Merino, S.; De Diego, G.; Namburi, H.; et al. Round Robin into Best Practices for the Determination of Indentation Size Effects. Nanomaterials 2020, 10, 130. [CrossRef] [PubMed]

25. Caillard, D. A TEM in situ study of alloying effects in iron. II-Solid solution hardening caused by high concentrations of Si and Cr. Acta Mater. 2013, 61, 2808-2827. [CrossRef]

26. Key, A.S.; Nakada, Y.; Leslie, W.C. Dynamic strain ageing in iron and steel. In Dislocation Dynamics; Rosenfield, A.R., Hahn, G.T., Bement, A.L., Jr., Jaffee, R.I., Eds.; McGraw-Hill Book Company: New York, NY, USA, 1968; pp. 381-408.

27. Roberts, M.J.; Owen, W.S. Unstable flow in martensite and ferrite. Metall. Trans. 1970, 1, 3203-3213.

28. Baird, J.D. The effects of strain ageing due to interstitial solutes on the mechanical properties of metals. Metall. Rev. 1971, $149,1-18$.

29. Hähner, P.; Ziegenbein, A.; Rizzi, E.; Neuhäuser, H. Spatiotemporal analysis of Portevin-Le Châtelier deformation bands: Theory, simulation, and experiment. Phys. Rev. B 2002, 65, 134109. [CrossRef] 